\title{
Domestic abuse before, during and after pregnancy in Jahrom, Islamic Republic of Iran
}

\author{
E. Mohammadhosseini, ${ }^{1}$ L. Sahraean ${ }^{2}$ and T. Bahrami ${ }^{2}$
}

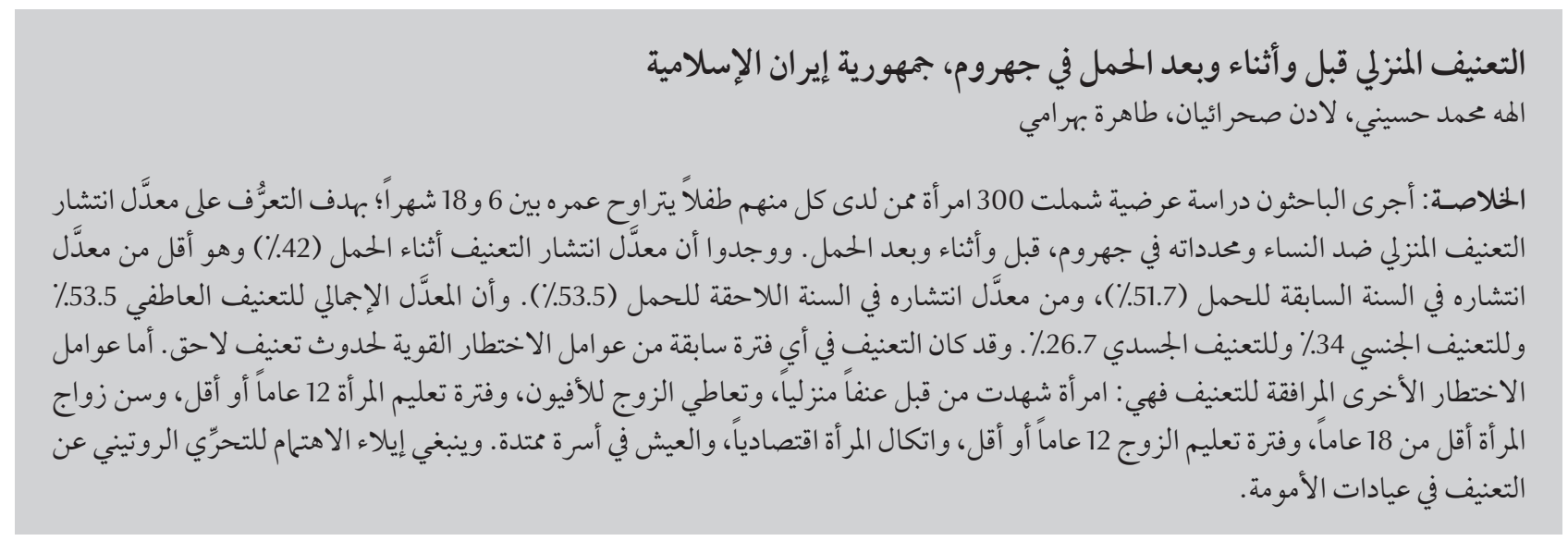

ABSTRACT We conducted a cross-sectional study among 300 women with a child aged 6 to 18 months, to determine the prevalence and determinants of domestic abuse against women in Jahrom; before, during and after pregnancy. The prevalence of abuse during pregnancy (42\%) was lower than during the 1 year before pregnancy $(51.7 \%)$ and after delivery (53.5\%). The overall prevalence of emotional abuse, sexual abuse and physical abuse was 53.5\%, $34.7 \%$ and $26.7 \%$ respectively. Abuse during any previous period was a strong risk factor for subsequent abuse. Other risk factors associated with abuse were: woman previously witnessing domestic violence, opium use by husband, woman's education $\leq 12$ years, age at marriage of woman $<18$ years, husband's education $\leq 12$ years, woman's economic dependency and living in an extended family. Routine screening of abuse in maternity clinics should be considered.

\section{Violence familiale avant, pendant et après la grossesse à Jahrom (République islamique d'Iran)}

RÉSUMÉ Nous avons réalisé une étude transversale auprès de 300 femmes ayant un enfant âgé de 6 à 18 mois, afin de d'identifier la prévalence et les déterminants de la violence familiale exercée avant, pendant et après la grossesse à l'encontre de femmes résidant à Jahrom (République islamique d'Iran). Au cours de la grossesse, la prévalence de la violence était plus faible (42\%) qu'au cours de l'année précédant la grossesse (51,7\%) et qu'après l'accouchement (53,5\%). La prévalence globale de la violence psychologique, sexuelle et physique s'élevait à 53,5\%,34,7\% et 26,7\%, respectivement. La violence durant toute période antérieure constituait un facteur de risque élevé de violence future. D'autres facteurs de risque étaient associés à la violence : femme ayant déjà assisté à des scènes de violence familiale, mari consommant de l'opium, femme instruite jusqu'à l'âge de 12 ans au maximum, femme mariée avant 18 ans, mari instruit jusqu'à l'âge de 12 ans au maximum, dépendance économique de la femme et vie dans une famille élargie. Un dépistage systématique de la violence lors des consultations en maternité devrait être envisagé.

${ }^{7}$ Department of Psychiatry, Medical College; ${ }^{2}$ Mental Health Centre, Jahrom University of Medical Sciences, Jahrom, Islamic Republic of Iran (Correspondence to E.Mohammadhosseini: emh_56@yahoo.com).

Received: 17/03/08; accepted: 20/07/08 


\section{Introduction}

According to world-wide studies, at least 1 in 5 women experiences a violent relationship at some point in their lives [1].

The World Health Organization (WHO) has defined domestic violence as "the range of sexually, psychologically and physically coercive acts used against adult and adolescent women by current or former male intimate partners" $[2,3]$.

Domestic violence is a particular problem in obstetric care. Studies suggest that pregnancy can act as a trigger for domestic violence or exacerbate an existing problem, although occasionally it has been associated with a reduction in violence [4].

Reported rates of physical, sexual or emotional violence during pregnancy range from $0.9 \%$ to $22 \%$ [5]. The risks of domestic violence are particularly acute in pregnancy, where the health and safety of 2 potential victims are placed in jeopardy. Domestic violence is associated with increased rates of miscarriage, premature birth [6], low birth weight, chorioamnionitis, fetal injury and fetal death $[7-10]$. Once the child is born, battered women are more likely to report child abuse or to fear it [7]. Studies of abuse in the year preceding pregnancy reported a prevalence ranging from $3.8 \%$ to $26 \%[11,12]$. However, women appear to be at even greater risk of domestic violence in the postpartum period compared with the time of pregnancy $[13,14]$.

According to some studies domestic violence is a common public health problem in the Islamic Republic of Iran [15-19], but to our knowledge few studies exist that compared the rate of domestic violence in pregnancy with rate of abuse before and after this period.

\section{Methods}

\section{Study design}

This was a descriptive, analytical cross-sectional study conducted from
November 2006 to January 2007 in Jahrom city in southern Islamic Republic of Iran.

\section{Sample}

Married women who had a child aged 6 to 18 months were the subjects of this study. Based on previous studies [15-19], the prevalence of wife abuse in the Islamic Republic of Iran ranges from $37 \%$ to $78 \%$. Therefore considering a lower approximate prevalence of $30 \%$ (0.3), the estimated sample size was $224[\mathrm{~d}=0.06,95 \%$ confidence interval (CI)]. A sample of 300 women was chosen to increase the statistical reliability of the study.

Immunization files in public health clinics served as the sampling frame. Public health clinics in the Islamic Republic of Iran are governmental clinics that provide some medical and primary health care services such as prenatal care, family planning and childhood immunization. In Jahrom, childhood immunization is exclusively done in these clinics and all children are brought there for vaccination. Often, husbands do not accompany their wives to the vaccination clinics and in our study if the husband was present, the woman was not enrolled.

There are 9 public health clinics in Jahrom city and each of them has a number. We started screening from clinic number 1 and subsequent days screening was done in other clinics (one clinic per day). Women were selected sequentially as an eligible woman (with a child aged 6 to 18 months) came in to the clinic for vaccination. After 9-11 days (because of holidays the cycle duration might be more than 9 days) we came back to the first clinic and continued this cyclical pattern until 300 women were entered in the study. In each of these clinics we interviewed about 33 (range: 31-35) women.

\section{Data collection}

Data were obtained by interview using a pretested questionnaire in Farsi which was derived from prior studies $[4,15,20]$. The questionnaire was administered by one clinical psychologist in complete privacy. Anonymity of the responses was assured and verbal consent to participate was obtained. The interviewer was a main manager of mental health programmes in public health clinics in Jahrom and many of the participants were familiar with her. Thus we did not face any refusals to participate in the study. The interview lasted for an average of 30 minutes.

\section{Questionnaire}

The questionnaire consisted of 2 parts. The first part obtained information regarding some demographic characteristics and the second part assessed abuse, including physical, emotional and sexual abuse, during each of 3 periods: the 12 months before pregnancy, the period of pregnancy and the time after delivery. The husbands were considered perpetrators of abuse in all questions. The face validity of the questionnaire was approved by 2 psychiatrists and a clinical psychologist and reliability analysis showed satisfactory results (Cronbach alpha coefficient $=0.7$ ).

Physical abuse was graded on 4 levels from mild (I) to severe (IV):

- Abuse involving beating or pushing but without trauma or persistent pain or limited movement of some parts of the body.

- Beating with persistent pain or limited movement of some parts of the body.

- Beating resulting in serious contusions, fractures or head or viscera trauma.

- Physical abuse with any implement, leading to permanent injury (for example blindness, lameness)

To assess sexual abuse, women were asked if they had been pressured verbally to have sexual intercourse, pressured with threats to have sexual intercourse or physically forced to have sexual intercourse. 


\begin{tabular}{|c|c|c|c|c|c|c|c|c|}
\hline \multirow[t]{2}{*}{ Period of abuse } & \multicolumn{2}{|c|}{ Emotional abuse } & \multicolumn{2}{|c|}{ Sexual abuse } & \multicolumn{2}{|c|}{ Physical abuse } & \multicolumn{2}{|c|}{ Any type ${ }^{a}$} \\
\hline & No. & $\%$ & No. & $\%$ & No. & $\%$ & No. & $\%$ \\
\hline Before pregnancy & 125 & 41.7 & 63 & 21 & 50 & 16.7 & 155 & 51.7 \\
\hline During pregnancy & 99 & 33.0 & 52 & 17.3 & 30 & 10.0 & 126 & 42.0 \\
\hline After pregnancy & 128 & 42.7 & 75 & 25 & 44 & 14.7 & 160 & 53.5 \\
\hline Overall $^{\mathrm{b}}$ & 160 & 53.5 & 104 & 34.7 & 80 & 26.7 & 194 & 64.7 \\
\hline
\end{tabular}

Women may have had more than 1 type of abuse and in more than 1 period. ${ }^{a}$ Any type of abuse, together. ${ }^{b}$ In all periods.

To assess emotional abuse, women were asked if they had been insulted or made to feel bad, humiliated in front of other people, threatened with divorce or abandonment or restricted access to family and friends.

Social support was assessed by asking whether the woman had any place where she could go and stay, if the condition in the house became intolerable.

An economically independent woman in this study was considered one who had a job or received financial support from another sources if deprived by her husband.

This study was supported by Jahrom of Medical Sciences and approved by the Ethics Committee of this university.

\section{Statistical analysis}

Data analysis was carried out using SPSS, version 12. Logistic regression models were applied to predict the factors that affected the risk of violence from husbands. Odds ratios (OR) and
95\% confidence intervals $(\mathrm{CI})$ were calculated. $P<0.05$ was considered significant.

\section{Results}

We interviewed 300 married women in the age group 18 to 40 years with a mean age of approximately 27 years [standard deviation (SD) 4.24]. Of these women, $53.3 \%$ had 1 child, $31.0 \%$ had 2 children and $15.7 \%$ had 3 or more children.

The overall prevalence of any abuse occurring in any period (before, during or after pregnancy) was $64.7 \%$. The overall prevalence of emotional abuse, sexual abuse and physical abuse was $53.5 \%, 34.7 \%$ and $26.7 \%$ respectively. Abuse during pregnancy was lower than that during the other 2 periods. The prevalence of abuse before, during and after pregnancy was $51.7 \%, 42.0 \%$ and $53.3 \%$ respectively. In all periods, emotional abuse was the most prevalent type of abuse and physical abuse was the least prevalent (Table 1). Most cases of physical abuse were not severe (Table 2).

A significant association was found between abuse before pregnancy and abuse during pregnancy $(\mathrm{OR}=27.31$; 95\% CI: $13.96-53.43)$. There was also a significant association between abuse before pregnancy and abuse after pregnancy (OR $=10.31$; 95\% CI: $6.04 \%-$ $17.59 \%)$ and between abuse during pregnancy and abuse after pregnancy $(\mathrm{OR}=29.73 \%$; 95\% CI: 14.68-60.22).

The prevalence of abuse with different variables is shown in Table 3.

All variables were considered for the logistic regression model to assess any confounding effects. On logistic regression analysis (Table 4), the strongest predictor of all types of abuse was women witnessing violence to other women by their husbands $(P<0.0001)$. In other words, women

\begin{tabular}{|c|c|c|c|c|c|c|c|c|c|c|}
\hline \multirow{2}{*}{$\begin{array}{l}\text { Period of physical } \\
\text { abuse }\end{array}$} & \multicolumn{2}{|c|}{ Level I } & \multicolumn{2}{|c|}{ Level II } & \multicolumn{2}{|c|}{ Level III } & \multicolumn{2}{|c|}{ Level IV } & \multicolumn{2}{|c|}{ Any level ${ }^{\mathrm{a}}$} \\
\hline & No. & $\%$ & No. & $\%$ & No. & $\%$ & No. & $\%$ & No. & $\%$ \\
\hline Before pregnancy & 47 & 15.7 & 15 & 5.0 & 15 & 5.0 & 2 & 0.7 & 50 & 16.7 \\
\hline During pregnancy & 23 & 7.7 & 5 & 1.7 & 8 & 2.7 & 0 & 0.0 & 30 & 10.0 \\
\hline After pregnancy & 37 & 12.3 & 15 & 5.0 & 15 & 5.0 & 2 & 0.7 & 44 & 14.7 \\
\hline Overall ${ }^{b}$ & 76 & 25.3 & 30 & 10.0 & 31 & 10.3 & 4 & 1.3 & 80 & 26.7 \\
\hline
\end{tabular}

${ }^{a}$ Any level of physical abuse; ${ }^{b}$ In all periods.

Women may have experienced more than 1 level of physical abuse and in more than 1 period.

Level I) Abuse involving beating or pushing but without trauma or persistent pain or limited movement of some parts of the body; Level II) Beating with persistent pain or limited movement of some parts of the body; Level III) Beating resulting in serious contusions, fractures or head or viscera trauma; Level IV) Physical abuse with any implement, leading to permanent injury (for example blindness, lameness). 
who, as children, had witnessed violence to women in their family by their husbands were more likely to be the victims of wife abuse. Overall incidence of wife abuse was also greater when the husband's education was $\leq 12$ years $(P=0.002)$. Strong predictors of physical abuse were: living in an extended family $(P=0.045)$, woman's education $\leq 12$ years $(P<0.0001)$, woman's economic dependency $(P<0.0001)$, husband's education $\leq 12$ years $(P=0.025)$, woman previously witnessing domestic violence $(P=0.001)$ and woman's age at marriage below 18 years $(P=0.007)$ (Table 4). The strongest predictor on logistic regression for sexual abuse was opium use by woman's husband $(P=0.01)$. For emotional abuse strong predictors of abuse on logistic regression were: opium use by husband $(P=0.045)$ and husband's education $\leq$ 12 years $(P=0.01)$. Husband's smoking, woman's age, parity and access to

\begin{tabular}{|c|c|c|c|c|}
\hline \multirow[t]{2}{*}{ Characteristic } & \multirow{2}{*}{$\begin{array}{c}\text { Total }(n=300) \\
\text { No. }\end{array}$} & \multicolumn{2}{|c|}{ Presence of domestic violence } & \multirow[t]{2}{*}{$P$-value } \\
\hline & & No. & $\%$ & \\
\hline Woman's years of education & & & & 0.08 \\
\hline $0-12$ & 237 & 159 & 67.1 & \\
\hline$>12$ & 63 & 35 & 55.5 & \\
\hline Type offamily & & & & 0.024 \\
\hline Nuclear family & 246 & 153 & 62.2 & \\
\hline Joint (extended) family & 54 & 42 & 77.7 & \\
\hline Witnessing abuse of another woman & & & & $<0.0001$ \\
\hline Yes & 163 & 123 & 75.5 & \\
\hline No & 137 & 71 & 51.8 & \\
\hline Social support & & & & 0.40 \\
\hline Present & 222 & 143 & 64.6 & \\
\hline Absent & 78 & 51 & 65.3 & \\
\hline Woman's economic status & & & & 0.39 \\
\hline Independent & 153 & 97 & 63.4 & \\
\hline Dependent & 147 & 97 & 66 & \\
\hline Woman's age & & & & 0.13 \\
\hline$<20$ & 19 & 15 & 78.9 & \\
\hline$\geq 20$ & 281 & 180 & 64 & \\
\hline Woman's age at marriage (years) & & & & 0.17 \\
\hline$<18$ & 127 & 87 & 68.5 & \\
\hline$\geq 18$ & 173 & 108 & 62.4 & \\
\hline Sex of child in index pregnancy & & & & 0.52 \\
\hline Female & 148 & 95 & 64.2 & \\
\hline Male & 152 & 98 & 64.5 & \\
\hline Parity & & & & 0.78 \\
\hline 1 & 160 & 103 & 64.4 & \\
\hline 2 & 93 & 59 & 63.4 & \\
\hline$\geq 3$ & 47 & 32 & 68.1 & \\
\hline Husband's years of education & & & & $<0.0001$ \\
\hline $0-12$ & 246 & 173 & 70.3 & \\
\hline$>12$ & 54 & 21 & 38.8 & \\
\hline Husband a cigarette smoker & & & & 0.12 \\
\hline Yes & 80 & 56 & 70 & \\
\hline No & 220 & 138 & 62.7 & \\
\hline Husband an opium user & & & & 0.012 \\
\hline Yes & 15 & 14 & 93.3 & \\
\hline No & 285 & 180 & 63.1 & \\
\hline
\end{tabular}




\begin{tabular}{|c|c|c|}
\hline Variable & OR $(95 \% \mathrm{Cl})$ & $P$-value \\
\hline \multicolumn{3}{|l|}{ Any type of abuse } \\
\hline Witnessing violence to another woman & $2.69(1.56-4.64)$ & $<0.0001$ \\
\hline Husband's education $\leq 12$ years & $3.22(1.52-6.84)$ & 0.002 \\
\hline \multicolumn{3}{|l|}{ Physical abuse } \\
\hline Living in an extended family & $2.32(1.01-5.30)$ & 0.045 \\
\hline Woman's education class level 12 or lower & $4.97(2.03-12.14)$ & $<0.0001$ \\
\hline Woman's age at marriage $<18$ years & $2.49(1.28-4.83)$ & 0.007 \\
\hline Woman's economic dependency & $3.98(1.99-8.00)$ & $<0.001$ \\
\hline Husband's education $\leq 12$ years & $3.43(1.16-10.10$ & 0.025 \\
\hline Witnessing violence to another woman & $2.93(1.51-5.67)$ & 0.001 \\
\hline \multicolumn{3}{|l|}{ Sexual abuse } \\
\hline Opium use by husband & $3.81(1.16-12.46)$ & 0.01 \\
\hline \multicolumn{3}{|l|}{ Emotional abuse } \\
\hline Opium use by husband & $8.59(1.04-69.8)$ & 0.045 \\
\hline Husband's education $\leq 12$ years & $2.66(1.26-5.61)$ & 0.01 \\
\hline
\end{tabular}

$O R=$ odds ratio $; C l=$ confidence interval.

social support were not associated with any type of abuse. There was no association between the sex of the child in the most recent pregnancy and incidence of abuse during the postpartum period.

In the perception of the women, poor relationship with the husband's family, discipline of the children and financial problems were the most frequent causes of abuse (Table 5).

\section{Discussion}

This is the first study in the Islamic Republic of Iran, to our knowledge, that examines women's pregnancy abuse experiences in comparison with abuse before and after pregnancy.

\begin{tabular}{lc}
\hline Table 5 Reasons for domestic abuse as cited by the women \\
\hline Reason for abuse & Frequency $(\%)(\boldsymbol{n}=\mathbf{3 0 0})$ \\
\hline Poor relationship with husband's family & 30.4 \\
Discipline of the children & 22.8 \\
Financial problems & 18.8 \\
Visiting her parents or friends & 8.8 \\
Unsatisfactory cooking or housekeeping & 3.5 \\
Other & 15.7 \\
Total & 100.0 \\
\hline
\end{tabular}

having engaged in non-consensual sex with their wives.

The prevalence of abuse during the pregnancy period (42\%) was relatively low compared with the prevalence of abuse during the 12 months before pregnancy $(51.7 \%)$ and after pregnancy (53.5\%) so it seems that pregnancy was a protective factor against wife abuse. The results from a number of other studies support this finding $[4,15,18]$. It may be related to a husband's worry about the health of the fetus.

The rates of physical, emotional and sexual abuse during pregnancy were respectively $10.0 \%, 33 \%$ and $17.3 \%$. In a study from Babol city (Islamic Republic of Iran) the rates of physical, emotional and sexual intimate partner abuse during pregnancy were $9.1 \%, 30.8 \%$ and $19.2 \%$ respectively [24]. In a hospitalbased study conducted in Tehran the prevalence of physical abuse during pregnancy was $10.7 \%$ [25]. The rates for physical abuse are all very similar to ours.

Although the prevalence of abuse in pregnancy was lower than the 2 another periods (before and after pregnancy), it is still much higher than that reported from some other countries: $4.3 \%$ in China, 28.4\% in India and 23\% in Pakistan $[4,20,26]$. In another study from Pakistan $44 \%$ of women reported abuse during index pregnancy; $43 \%$ of these experienced emotional abuse and $12.6 \%$ reported physical abuse [27]. These variations in results may reflect different definitions of abuse, the screening method used or cultural differences.

We found that women were at greater risk of domestic abuse in the postpartum period, so more attention should be paid to high-risk women in this period.

In all 3 periods, emotional abuse was the most prevalent type of abuse, followed by sexual abuse and physical abuse.

Consistent with a similar study in China [4], we also found that abuse 
before pregnancy was a strong risk factor for abuse during pregnancy and after pregnancy. In general, abuse during a previous period was a strong risk factor for subsequent abuse. According to these results, women who were abused before pregnancy should be considered a high risk group for abuse during pregnancy and in the postpartum period.

Several risk factors were associated with abuse. There was a strong positive association between a woman witnessing abuse and being a victim of abuse, consistent with the findings of Su-Fang et al. [4]. This lends support to the fact that domestic violence is a learned behaviour and many of these women learned helplessness and acceptance of violence many years before [4].

Living in an extended familyincreased the chance of physical abuse. It seems that family conflicts were more frequent or greater in the setting of an extended family. Similar association between this factor and emotional abuse was found by Su-fang and colleagues [4].

The risk of physical abuse was greater when the women's education was $\leq 12$ years. In many previous studies, high education level was associated with lower levels of violence $[18,28-32]$, although in a study from India [20] high educational level did not have a protective role against wife abuse. Women with economic independence experienced physical abuse less than others. This demonstrates the protective effect of financial independence of women against violence, which concurs with some previous studies $[18,33,34]$, although a number of other studies do not support this finding $[20,28,35]$.

Another predictor of a higher rate of physical abuse was woman's age at marriage $>18$ years: when a girl marries in adolescence, she is at higher risk of abuse by her husband and abuse probably continues for the duration of the marriage. It has been reported that wife abuse itself is reinforcing; once a man has beaten his wife, he is likely to do so again [36].
The incidence of physical and emotional abuse were increased when the husband's education level was $\leq$ 12 years. Similar results were reported by Khosla and colleagues [20] among Indian women but other studies did not find such association $[16,35,37,38]$.

Positive history of opium use in women's husbands was associated with a higher rate of emotional and sexual abuse. The results of 2 studies conducted in the Islamic Republic of Iran support this finding $[15,16]$.

There was no relationship between domestic abuse and social support, which is surprising because social support should discourage tolerance of abuse. It is possible that our assessment of social support was inadequate and we did not consider the accessibility of women to all types of social support services.

We predicted that violence against women who gave birth to a female infant would increase in the postpartum period because in many countries such as the Islamic Republic of Iran parents are sensitive to a child's sex and there is a preference for male infants. However, the sex of child in the most recent pregnancy had no effect on the incidence of wife abuse in this period. It may be related to the promotion of the socioeconomic status of women in recent years. Women now can be educated and work like a man and this fact may reduce the sensitivity of parents to the sex of a child. It may also be that the sex issue is influenced by some other factors, such as parity and the sex of other children in the family, and we did not evaluate this.

Our study has some limitations. It was a retrospective study and the results may be influenced by some recall bias. The study is also subject to selection bias as women whose husbands came with them were excluded and they may be significantly different from those whose husbands did not come in relation to abuse. In addition, our definition of wife abuse was limited to some specific types of abuse and if we considered more details and subtypes of abuse (e.g. withdrawal of money, eviction from the house), the actual prevalence of abuse may be higher than our results indicate. Participants in this study were selected from specific group and our results cannot be generalized to all women of Jahrom. A populationbased study is required to assess the frequency and risk factors of wife abuse in this city.

In conclusion, the prevalence of domestic abuse in this community sample is very high and women are particularly vulnerable during pregnancy and the postpartum period. The actual prevalence of abuse may be even higher than our research has shown because of the shame traditionally associated with disclosing domestic violence.

Pregnant women are not routinely screened for the presence of domestic violence in the Islamic Republic of Iran. However, given the high level observed in our study, routine screening of abuse in maternity clinics is advocated. All health care providers, especially midwives, general practitioners and obstetricians, should be educated to identify and detect domestic violence in order to decrease the adverse impact of violence on women and their babies. While there are no formal provisions currently in the system for dealing with spousal abuse, other than counselling and advice, it is hoped that identifying the problem and drawing attention to its prevalence will enhance the awareness and sensitivity of health care providers to this issue and the need to address it.

\section{Acknowledgements}

We would like to thank the women that participated in this study for their cooperation.

We would also like to express our appreciation to the staff of Jahrom public health clinics for their assistance in this project. 


\section{References}

1. Violence against women. Geneva, World Health Organization, 2001 (WHO fact sheet, No. 239).

2. Kocacik F, Dogan O. Domestic violence against women in Sivas, Turkey: Survey study. Croatian Medical Journal, 2006 , 47(5):742-749

3. Violence against women: a priority health issue. Geneva, World Health Organization, 1997 (WHO document WHO/FRH/ WHD/97.8\#).

4. Su-Fang G et al. Domestic abuse on women in China before, during, and after pregnancy. Chinese Medical Journal, 2004, 117(3):331-336.

5. Bacchus $L$ et al. Domestic violence in pregnancy. Fetal Maternal Medical Review, 2001, 12:249-271.

6. Berenson $\mathrm{AB}$ et al. Perinatal morbidity associated with violence experienced by pregnant women. American Journal of Obstet rics and Gynecology, 1194, 1170:1760-1769.

7. Stark E et al. Medical and patriarchal violence: the social construction of a "private" event. International Journal of Health Services, 1979, 9:461-493.

8. Hiberman E et al. Sixty battered women. Victimology: an International Journal, 1978, 2:460-470.

9. Bohn DK. Domestic violence and pregnancy. Implication for practice. Journal of Nurse-midwifery, 1990, 35:80-86.

10. Webster J et al. Pregnancy outcomes and health care use - effects of abuse. American Journal of Obstetrics and Gynecology, 1996, 174:760-767.

11. From the Centers for Disease Control and Prevention. Physical violence during the 12 months preceding childbirth - Alaska, Maine, Oklahoma, and West Virginia, 1990-1991. Journal of the American Medical Association, 2000, 271:1152-1153.

12. Sandra LM et al. Physical abuse of women before, during and after pregnancy. Journal of the American Medical Association, 2001, 285:1581-1584.

13. Hedin-Widding $L$ et al. Postpartum, also a risk period for domestic violence. European Journal of Obstetrics and Gynecology, 2000, 89:41-45.

14. Gielen $\mathrm{A}$ et al. Interpersonal conflict and physical violence during the childbearing year. Social Science \& Medicine, 1994, 39:781-787.

15. Jokar A et al. [A study on prevalence rate of intimate partner violence among women attending Yasuj health centers] Armaghane-Danesh, Journal of Yasuj University of Medical Sciences, 2005, 37(10):81-88 [In Farsi].

16. Mousavi SM et al. Wife abuse in Esfahan, Islamic Republic of Iran, 2002. Eastern Mediterranean Health Journal, 2005 11(5-6):860-869.

17. Ghazizadeh A. Domestic violence: a cross-sectional study in an Iranian city. Eastern Mediterranean Health Journal, 2005 11(5-6):880-887.

18. Faramarzi $\mathrm{M}$ et al. Prevalence and determinants of intimate partner violence in Babol city, Islamic Republic of Iran. Eastern Mediterranean Health Journal, 2005, 11(5-6): 870-879.

19. Nojomi M, Agaee S, Eslami S. Domestic violence against women attending gynecologic outpatient clinics. Archives of Iranian Medicine, 2007, 10(3):309-315.
20. Khosla AH et al. Domestic violence in pregnancy in North Indian women. Indian Journal of Medical Sciences, 2005, 59(5):195-199.

21. Yoshihama $\mathrm{M}$ et al. Experiences of intimate partner violence and related injuries among women in Yokohama, Japan. American Journal of Public Health, 2007, 97(2):232-240.

22. Neroien $\mathrm{Al}$, Scheis B. Partner violence and health: results from the first national study on violence against woman in Norway. Scandinavian Journal of Public Health, 2008, 36(2):161-168.

23. Shaikh MA. Domestic violence against women - perspective from Pakistan. Journal of the Pakistan Medical Association, 2000, 50(9):312-314.

24. Faramarzi M et al. Prevalence, maternal complications and birth outcome of physical, sexual and emotional domestic violence during pregnancy. Acta Medica Iranica, 2005, 43(2):115-122.

25. Nojoumi M, Akrami Z. [Physical violence during pregnancy: Prevalence and outcomes]. Payesh, Journal of the Iranian Institute for Health Sciences Research, 2003, 1(2):43-48 [In Farsi].

26. Fikree FF et al. Intimate partner violence before and during pregnancy: experience of postpartum women in Karachi, Pakistan. Journal of the Pakistan Medical Association, 2006, 56(6):252-257

27. Farid $\mathrm{M}$ et al. Spousal abuse during pregnancy in Karachia, Pakistan. International Journal of Gynecology and Obstetrics, 2008, 101(2):141-145.

28. Jewkes R, Levin J, Penn-Kekana L. Risk factors for domestic violence: findings from a South African cross-sectional study. Social Science \& Medicine, 2002, 55(9):1603-1617.

29. Steinmetz SK. Family violence: past, present and future. In: Sussman MB, Steinmetz SK, eds. Handbook of Marriage and the Family. New York, Plenum Press, 1987:725-765.

30. Straus MA, Gelles RJ, Steinmetz SK. Behind closed doors: Violence in American family. New York, Anchor Press, 1980.

31. Wadman MC, Mulleman RL. Domestic violence homicides: ED use before victimization. American Journal of Emergency Medicine, 1999, 17:689-691.

32. McCall GJ, Shields NM. Social and structural factors in family violence. In: Lystad M, ed. Violence in the home: interdisciplinary perspectives. New York, Brunner-Mazel, 1986.

33. Schuler SR et al. Credit programmes, patriarchy and men's violence against women in rural Bangladesh. Social Science \& Medicine, 1996, 43:1729-1742.

34. Rao V. Wife-beating in rural south India: a qualitative and econometric analysis. Social Science \& Medicine, 1997, 44:11691180.

35. Ellsberg MC et al. Wife abuse among women of childbearing age in Nicaragua. American Journal of Public Health, 1999, 89:241-244.

36. Sadock BJ, Sadock VA. Synopsis of psychiatry. New York, Lippincott Williams and Wilkins Press, 2007.

37. Deyessa $\mathrm{N}$ et al. Magnitude, type and outcomes of physical violence against married women in Butajira, southern Ethiopia. Ethiopian Medical Journal, 1998, 36(2):83-92.

38. Plichta SB, Duncan MM, Plichta L. Spouse abuse, patientphysician communication, and patient satisfaction. American Journal of Preventive Medicine, 1996, 12(5):297-303. 